\title{
Effect of Solvent Evaporation Time and Casting Thickness on the Separation Performance of Cellulose Acetate Butyrate Blend Membrane
}

\author{
Darvin Manimaran ${ }^{\mathrm{a}}$, Zeinab Abbas Jawad ${ }^{\mathrm{a} *}$ \& Chew Thiam Leng ${ }^{\mathrm{b}, \mathrm{c}}$ \\ aDepartment of Chemical Engineering, Faculty of Engineering and Science, Curtin \\ University Malaysia, CDT 250, 98009 Miri, Sarawak, Malaysia \\ ${ }^{b}$ Department of Chemical Engineering, Faculty of Engineering, Universiti Teknologi \\ PETRONAS, 32610 Seri Iskandar, Perak, Malaysia \\ ${ }^{\mathrm{c}} \mathrm{CO}_{2}$ Research Centre (CO2RES), Institute of Contaminant Management, Universiti \\ Teknologi PETRONAS, 32610 Seri Iskandar, Perak, Malaysia
}

Submitted: 25/1/2019. Revised edition: 19/4/2019. Accepted: 25/4/2019. Available online: 15/7/2019

\begin{abstract}
Global warming and climate change due to greenhouse gases (GHGs) emission, mostly carbon dioxide $\left(\mathrm{CO}_{2}\right)$, have induced global efforts to minimize the concentration of atmospheric $\mathrm{CO}_{2}$. To reduce the effects of this problem, membrane technology is selected for the separation of $\mathrm{CO}_{2}$ due to the energy efficiency and economic advantages exhibited. In this study, the chosen polymeric material, cellulose acetate butyrate (CAB) is optimized using a wet phase inversion method with various molecular weight and different casting conditions due to its outstanding film-forming specifications and capabilities of fabricating a defect-free layer of neat membrane. The membrane was synthesized by blending three different molecular weights $(\mathrm{Mn})$ of 12,000, 30,000 and 70,000 at different casting thickness, $150 \mu \mathrm{m}$ to $300 \mu \mathrm{m}$ and solvent evaporation time of 3.5 to $5 \mathrm{~min}$. The results of these predominant parameters were then utilized to determine a high performance $\mathrm{CAB}$ membrane suitable for an enhanced $\mathrm{CO}_{2} /$ Nitrogen $\left(\mathrm{N}_{2}\right)$ separation. Eventually, a high separation performance $\mathrm{CAB}$ membrane was successfully synthesized with a $\mathrm{CO}_{2} / \mathrm{N}_{2}$ selectivity of $1.5819 \pm 0.0775$ when the solvent evaporation time and casting thickness was optimized at $4.5 \mathrm{~min}$ and $300 \mu \mathrm{m}$, respectively. Through this study, an improved understanding between membrane casting conditions and membrane performance has been achieved, for future development and progress.
\end{abstract}

Keywords: Cellulose acetate butyrate, casting thickness, solvent evaporation time, polymer molecular weight, $\mathrm{CO}_{2} / \mathrm{N}_{2}$ separation

\subsection{INTRODUCTION}

The continued development of climate change due to greenhouse gasses (GHGs) emission, mostly carbon dioxide $\left(\mathrm{CO}_{2}\right)$ has become a severe concern globally [1]. Therefore, wellconstructed solutions and adaptation strategies, if adopted quickly, could significantly reduce the effects of climate change. Membrane gas separation technology can be one of the approaches examined to address the increased levels of atmospheric $\mathrm{CO}_{2}$ [2].

Membrane separation is extensively investigated, as it has numerous advantages [3] compared to conventional processes, such as low capital and operating cost, lower energy requirements, basic process configuration as well as minimized 
footprint [4]. Furthermore, the performance of polymeric membrane, the most commonly studied $\mathrm{CO}_{2}$ membrane technology, is defined by the relationship between selectivity and permeability, which is also the main challenge in the permeation technology [1].

The polymeric membrane fabrication is controlled by a variation of parameters that would ultimately affect the permeability and selectivity of the membrane. Casting thickness is one of the important parameter as it influences the membrane morphology and separation performance which would directly influence the efficiency of the gas separation [5]. According to Jawad et al. (2015), a thin membrane layer is essential to achieve a high efficiency [6]. This is because, the gas permeability of the membrane increases as the thickness layer decreases [7].

Besides that, solvent evaporation time is also another influential parameter as it affects the formation of undesired macrovoids [8]. According to Holda et al. [9], the membrane skin layer decreases with an increased evaporation time leading to morphologies with less macrovoid in the substructure. This allows gas to pass through the membrane structure at a faster rate. Hence, according to Lee et al. [2], the dominant specification for solvent evaporation time was 5 minutes as a better selectivity and consistent permeances result were observed for cellulose acetate butyrate (CAB) with molecular weight (Mn) of 70000.

Thus, the aim of this research project is to produce a high efficiency performance of $\mathrm{CAB}$ polymer matrix for the improvement of $\mathrm{CO}_{2} / \mathrm{N}_{2}$ separation. Up to date, many works have been conducted, aimed at enhancing membrane performance for numerous membrane separation processes. However, there is no research study combined the effect of membrane casting thickness and solvent evaporation time, together with the molecular weight of $\mathrm{CAB}$ of $12,000,30,000$ and 70,000 at a ratio of $1: 2: 2$ for gas separation. This is because Mn of polymeric membranes has a momentous influence on the rheology of the polymer solution which manipulates the structure and the performance of the final membranes [10]. Therefore, by synthesizing a membrane by blending three different molecular weights of $\mathrm{CAB}$, the membrane surface hydrophilicity can be improved because of the presence of the extra hydroxyl $(\mathrm{O}-\mathrm{H})$ and carbonyl groups $(\mathrm{C} \equiv \mathrm{O})$ originating from the $\mathrm{CAB}$ of each $\mathrm{Mn}$ [11]. In addition, these highly polar functional groups, $\mathrm{C} \equiv \mathrm{O}$ and $\mathrm{O}-\mathrm{H}$, can react with the non-polar $\mathrm{CO}_{2}$ gas [12]. Hence, enhancing the $\mathrm{CO}_{2}$ permeability and selectivity of the CAB membrane [13]. Therefore, this research study is believed to further improve the membrane design for gas separation

\subsection{METHODS}

\subsection{Materials}

The cellulose acetate butyrate (CAB) with acetyl content of $12 \%-15 \%$ and polymer molecular weights $(\mathrm{Mn})$ of $12,000,30,000$, and 70,000 was purchased from Sigma-Aldrich (Malaysia) for membrane fabrication. The solvent chloroform $(99.7 \%)$ was purchased from Merck (Malaysia). The hexane (99.8\%) and isopropyl alcohol $(99.6 \%)$ were supplied by Merck (Malaysia) for membrane drying. Purified carbon dioxide $\left(\mathrm{CO}_{2}\right)$ and nitrogen $\left(\mathrm{N}_{2}\right)$ were acquired from Linde EOX Sdn Bhd (Malaysia). 
Table 1 The composition of membrane fabricated at different casting thickness

\begin{tabular}{|c|c|c|c|c|c|c|c|}
\hline \multicolumn{4}{|c|}{ CAB Polymer } & \multicolumn{2}{|c|}{ Solvent (Chloroform) } & \multirow{3}{*}{$\begin{array}{c}\text { Casting } \\
\text { thickness } \\
(\mu \mathrm{m})\end{array}$} & \multirow{3}{*}{$\begin{array}{c}\text { Sample } \\
\text { Description }\end{array}$} \\
\hline \multirow{2}{*}{$\begin{array}{l}\text { Total } \\
(\text { wt } \%)\end{array}$} & \multicolumn{3}{|c|}{$\begin{array}{l}\text { Molecular Weight, Mn } \\
\text { (g) }\end{array}$} & \multirow{2}{*}{$(w t \%)$} & \multirow{2}{*}{ (ml) } & & \\
\hline & 12,000 & $\mathbf{3 0 , 0 0 0}$ & 75,000 & & & & \\
\hline 4 & 0.8 & 1.6 & 1.6 & 96 & 64 & 150 & M5 \\
\hline 4 & 0.8 & 1.6 & 1.6 & 96 & 64 & 250 & M6 \\
\hline 4 & 0.8 & 1.6 & 1.6 & 96 & 64 & 300 & M7 \\
\hline
\end{tabular}

Table 2 The composition of membrane fabricated at different solvent evaporation time

\begin{tabular}{|c|c|c|c|c|c|c|c|}
\hline \multicolumn{4}{|c|}{ CAB Polymer } & \multicolumn{2}{|c|}{$\begin{array}{c}\text { Solvent } \\
\text { (Chloroform) }\end{array}$} & \multirow{3}{*}{$\begin{array}{c}\text { Solvent } \\
\text { Evaporation } \\
\text { Time } \\
(\text { min) }\end{array}$} & \multirow{3}{*}{$\begin{array}{c}\text { Sample } \\
\text { Description }\end{array}$} \\
\hline \multirow{2}{*}{$\begin{array}{l}\text { Total } \\
(\mathbf{w t} \%)\end{array}$} & \multicolumn{3}{|c|}{$\begin{array}{c}\text { Molecular Weight, Mn } \\
\text { (g) }\end{array}$} & \multirow{2}{*}{$(w t \%)$} & & & \\
\hline & 12,000 & 30,000 & 75,000 & & (ml) & & \\
\hline 4 & 0.8 & 1.6 & 1.6 & 96 & 64 & 3.5 & M1 \\
\hline 4 & 0.8 & 1.6 & 1.6 & 96 & 64 & 4 & M2 \\
\hline 4 & 0.8 & 1.6 & 1.6 & 96 & 64 & 4.5 & M3 \\
\hline 4 & 0.8 & 1.6 & 1.6 & 96 & 64 & 5 & M4 \\
\hline
\end{tabular}

\subsection{Fabrication of CAB Membrane}

Wet phase inversion method was used for the fabrication process of CAB. Phase inversion can be expressed as a demixing procedure whereby the initially homogenous polymer solution was transformed in a controlled manner from a liquid to solid state [14]. The experiment was initiated by preparing a solution consisting of 4 $\mathrm{wt} \%$ of $\mathrm{CAB}$ and $96 \mathrm{wt} \%$ of chloroform [2]. The prepared solution was then stirred for $24 \mathrm{hrs}$ before being sonicated for $20 \mathrm{~min}$. The sonication procedure is essential to establish the surface of the neat membrane by eliminating the bubbles in the solution [15]. The next step was casting the membrane with a casting thickness of $150 \mu \mathrm{m}$ using a casting machine. This is followed by the solvent evaporation for 4.5 minutes at room temperature.
To phase out the residual solvent, the membrane was immersed in a distilled water at a temperature of $22{ }^{\circ} \mathrm{C}$ for 24 hrs. Later, the fabricated membrane was immersed in isopropyl alcohol and then n-hexane accordingly for $1 \mathrm{hr}$ each. This step was performed to dry the membrane formed. Finally, to eliminate all the excess solvents, the fabricated membrane, was heated in an oven at a temperature of $70{ }^{\circ} \mathrm{C}$ for 24 hrs. All the mentioned steps were performed respectively for CABs with different molecular weight distribution ranging from $\mathrm{Mn} 12,000$ to $\mathrm{Mn}$ 70,000 .

\subsection{Effect of Casting Thickness}

In this study, the membrane was fabricated at different casting thickness ranging from $150 \mu \mathrm{m}$ to $300 \mu \mathrm{m}$ with a constant solvent evaporation time of 


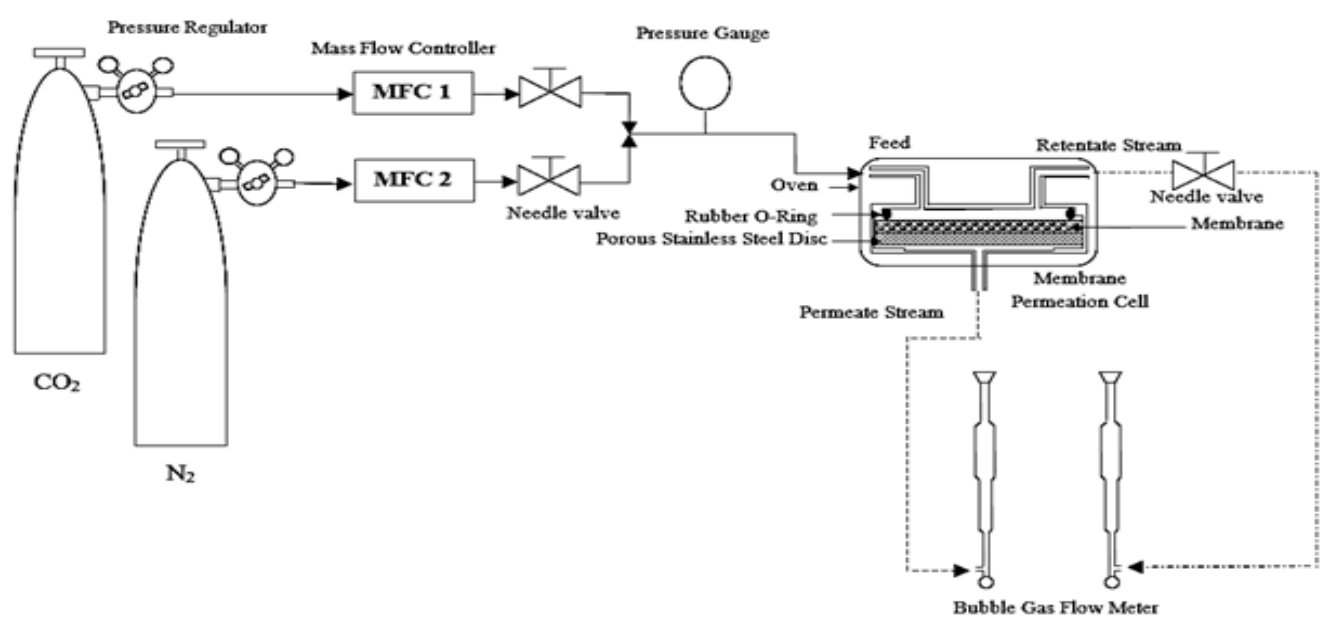

Figure 1 Illustrative diagram of the experimental set-up [2]

4.5 min. The composition of the membrane fabrication is exhibited in Table 1.

\subsection{Effect of Solvent Evaporation Time}

In this study, the membrane was fabricated at different solvent evaporation time ranging from 3.5 to 5 minutes with a constant membrane thickness of $250 \mu \mathrm{m}$. The composition of the membrane fabrication is exhibited in Table 2.

\subsection{Gas Permeation Test}

Purified $\mathrm{CO}_{2}$ and $\mathrm{N}_{2}$ at room temperature was utilized for the gas permeation test. For each single gas permeation test $\left(\mathrm{CO}_{2}\right.$ or $\left.\mathrm{N}_{2}\right)$, the flow rate of the gas was set to release from a compressed gas cylinder tank at a rate of $100 \mathrm{ml} / \mathrm{min}$ employing a mass flow controller (Aalborg AFC 26, USA). As shown in Figure 1, the mass flow controller was linked to a two-channel digital set point/readout unit (Aalborg $0-200 \mathrm{ml} / \mathrm{min}$, USA). Throughout the experimental investigation, the selected gas was fed into the stainlesssteel membrane cell at a pressure ranging from 1-2 bar. To ensure reliable and accurate results, several precautionary measures were established prior to the membrane testing. First, $\mathrm{N}_{2}$ gas was streamed through the set up for 10 minutes, to remove any impurity gas within the pipes. This procedure was conducted to prevent leakage and guarantee no feed gas outbreak from the pipes. Next, the synthesized membrane was shaped into a round disc with an approximate diameter of $7.065 \mathrm{~cm}^{2}$ before being placed in the firmly covered membrane permeation cell. Then, the flowrate of the permeate and retentate was studied individually utilizing the volume displacement method, aided by a soap bubble flow meter [2].

\subsection{Gas Separation Performance}

The gas permeation and separation performance, was obtained using the following equations and calculations:

Flux of the gas sample, $N_{i}$ was calculated by the following equation: $N_{i}$

$=\frac{\text { mol of component gas A permeate through membrane }}{t A_{m}}$

where $N_{i}=$ Flux of gas, $\mathrm{mol} / \mathrm{m}^{2} . \mathrm{s}, A_{m}$ $=$ Area, $\mathrm{m}^{2}, \mathrm{t}=$ time, $\mathrm{s}$ and $i=$ Refer to the gas $\mathrm{CO}_{2}$ or $\mathrm{N}_{2}$

Permeability of the membrane, $P_{i}$ was obtained by the following equation: 
$P_{i}=\frac{N_{i}}{\Delta P_{i}}$

where $P_{i}=$ Permeability of membrane, $\mathrm{mol} / \mathrm{m}^{2}$. s. $\mathrm{Pa}$ and $\Delta P_{i}=$ Pressure difference across the membrane, $\mathrm{Pa}$.

Ratio of permeability, $\alpha_{i j}$ of $\mathrm{CO}_{2} / \mathrm{N}_{2}$ was calculated by the following equation:

$\alpha_{i j}=\frac{P_{i}}{P_{j}}=\frac{P_{i} / l}{P_{j} / l}$

\subsection{Characterization of Membrane}

Scanning Electron Microscope (SEM) and Attenuated Total Reflectance Fourier transform infrared spectroscopy (ATR-FTIR) were used for the characterization of the synthesized membrane.

\subsubsection{Scanning Electron Microscope (SEM)}

A scanning electron microscope is a highly versatile electron beam instrument that can produce images over 100 times more magnified than commercial optical microscopes. It scans a focused electron beam over a surface to form an image. The electron in the beam interacts with the sample, generating various signals that can be used to acquire information about the surface topography and composition [16]. For this study, a scanning electron microscope (Hitachi TM3000, Japan) was used to establish the membrane surface morphology and cross-sectional structure.

To carry out SEM characterization, the membrane samples was first cut into small pieces before freezing it in a cryogenic freezer with a petri dish at $80{ }^{\circ} \mathrm{C}$ for 24 hours. This step was carried out to ensure the membrane structure is consistent and not deformed. Next, the samples were coated with platinum before being observed under the microscope to stop the accumulation of static charges at the specimen.

\subsubsection{Attenuated Total Reflectance Fourier Transform Infrared Spectroscopy (ATR-FTIR)}

Attenuated Total Reflectance Fourier transform infrared (ATR-FTIR) spectroscopy is a type of spe trosferiby 3 where infrared light is introduced into a prism at an angle beyond the critical angle for internal reflection. This allows the measurement of depth profiles for thin layers and the orientation of molecules adsorbed on the surface [17]. For this study, the ATR-FTIR was used to identify and understand the membrane structure. This method normally does not require any sample preparation.

Hence, the samples were tested using a Thermo Scientific Fourier transform infrared spectrometer (Nicolet iS10, USA) over the wavenumber range of $425-4000 \mathrm{~cm}^{-1}$. Each spectrum was established from 32 scans at $4 \mathrm{~cm}^{-1}$ with a resolution of $45^{\circ}$ incident angle with the help of a diamond crystal.

\subsection{RESULTS AND DISCUSSION}

\subsection{Effect of Casting Thickness}

\subsubsection{Membrane Characterization}

SEM analysis had been carried out to study the membrane morphology and membrane thickness. Figure 2 demonstrates the surface morphology and cross-sectional thickness for the $\mathrm{CAB}$ membranes fabricated at different casting thickness of $150 \mu \mathrm{m}$ (M5), $250 \mu \mathrm{m}$ (M6) and $300 \mu \mathrm{m}$ (M7), respectively. Based on Figure 2 (a, c and e), the membrane surface is rough for all casting thickness. In addition, the formation of nodules reduced with 
increase the casting thickness of the membrane. This is as a results of the low evaporation rate at high casting thickness Therefore, the nodular structures can aggregate to form less structures [18]. Besides that, according to Figure 2 (b, d and $\mathrm{f}$ ), when the casting thickness increased from 150 $\mu \mathrm{m}$ (M5) to $300 \mu \mathrm{m}$ (M7), the membrane thickness also increased from $4.852 \pm 0.654 \mu \mathrm{m}$ to $28.4455 \pm$ $1.314 \mu \mathrm{m}$. This is due to the slower polymer deposition speed as more
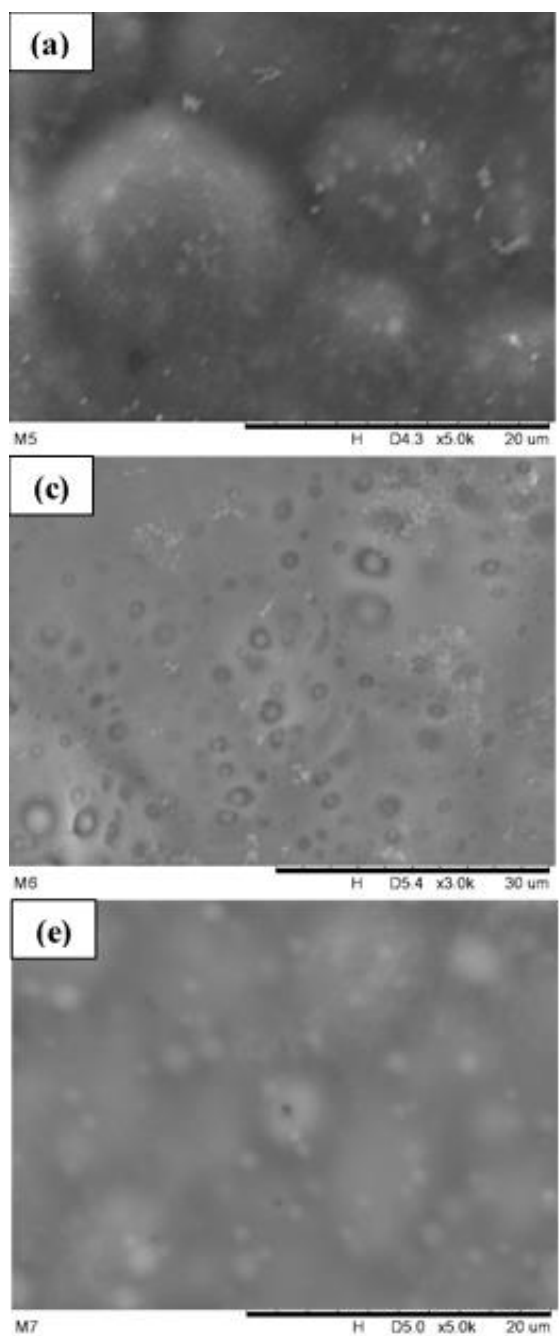

layers were involved in the membrane formation when the membrane was fabricated with a thicker casting thickness. Additionally, the kinetic of phase separation would also be delayed, enabling the combination of polymer-lean domains which are positioned below the membrane-air interface. Hence, forming a thicker membrane as the casting thickness increases [19].
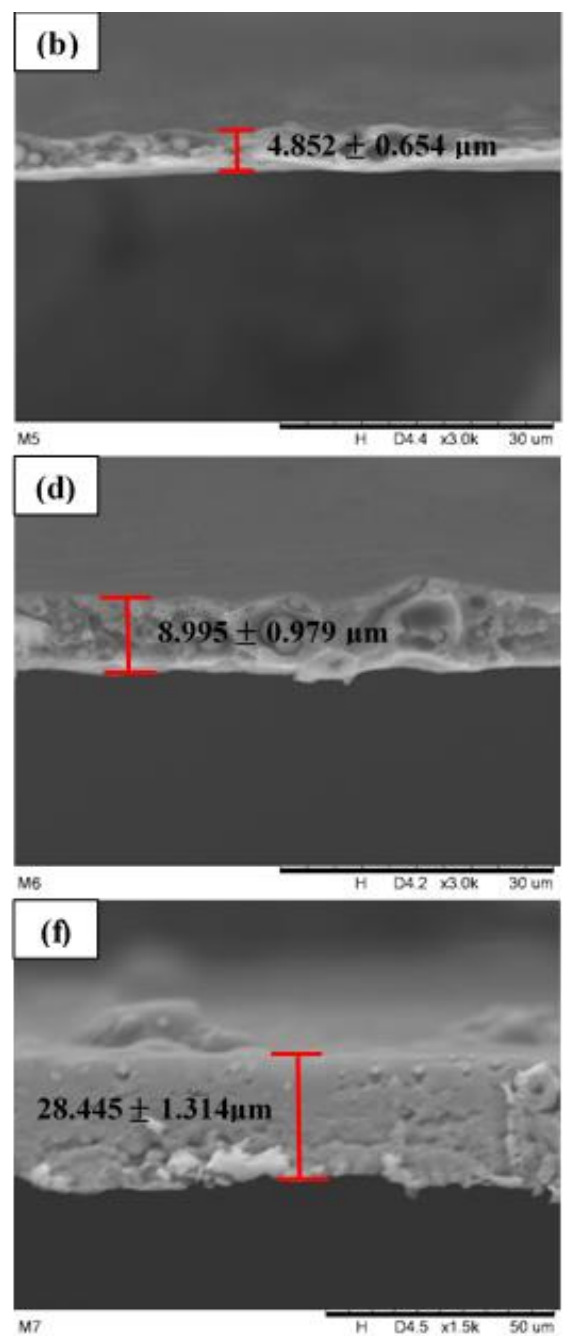

Figure 2 SEM micrographs of membrane surface (left) and cross-section (right) structure synthesized by using $4 \mathrm{wt} \%$ of $\mathrm{CAB}$ Polymer concentration made up by blending three different molecular weights $(\mathrm{Mn})$ of $12,000,30,000$ and 70,000 at a ratio of 1:2:2, solvent evaporation time of $4.5 \mathrm{~min}$, and solvent exchange drying time of 1 hour for 2-isopropyl alcohol and n-hexane each, with different casting thickness of (a-b) $150 \mu \mathrm{m}$ (M5), (c-d) $250 \mu \mathrm{m}$ (M6), and (e-f) $300 \mu \mathrm{m}$ (M7) 


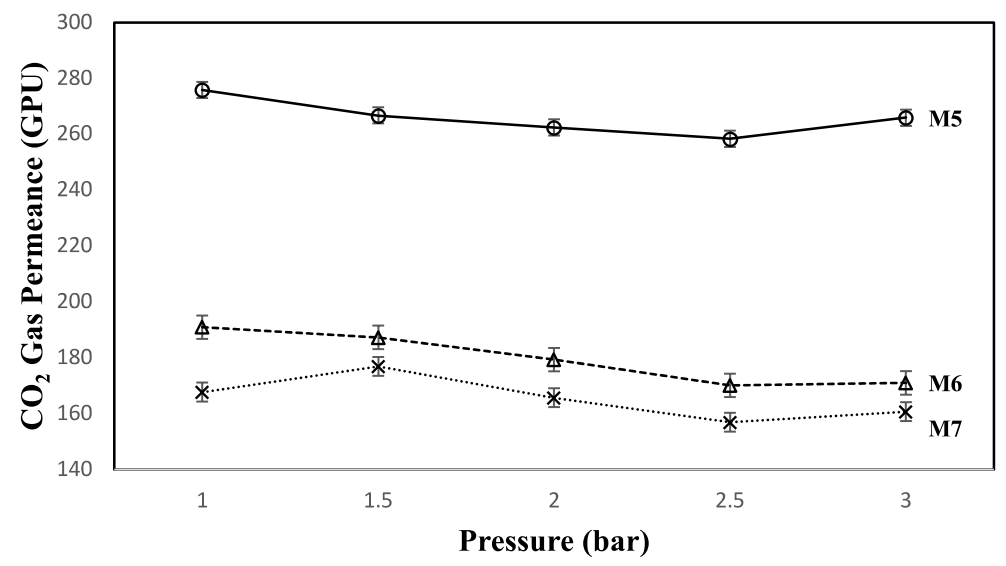

Figure $3 \mathrm{CO}_{2}$ Permeance for $\mathrm{CAB}$ membrane fabricated with different casting thickness of 150 $\mu \mathrm{m}$ (M5), $250 \mu \mathrm{m}$ (M6), and $300 \mu \mathrm{m}$ (M7) with solvent evaporation time of $4.5 \mathrm{~min}$, polymer concentration of $4 \mathrm{wt} \%$ made up by blending three different molecular weights $(\mathrm{Mn})$ of 12,000, 30,000 and 70,000 at a ratio of 1:2:2, and solvent exchange drying time of 1 hour each for 2isopropyl alcohol and $n$-hexane, respectively

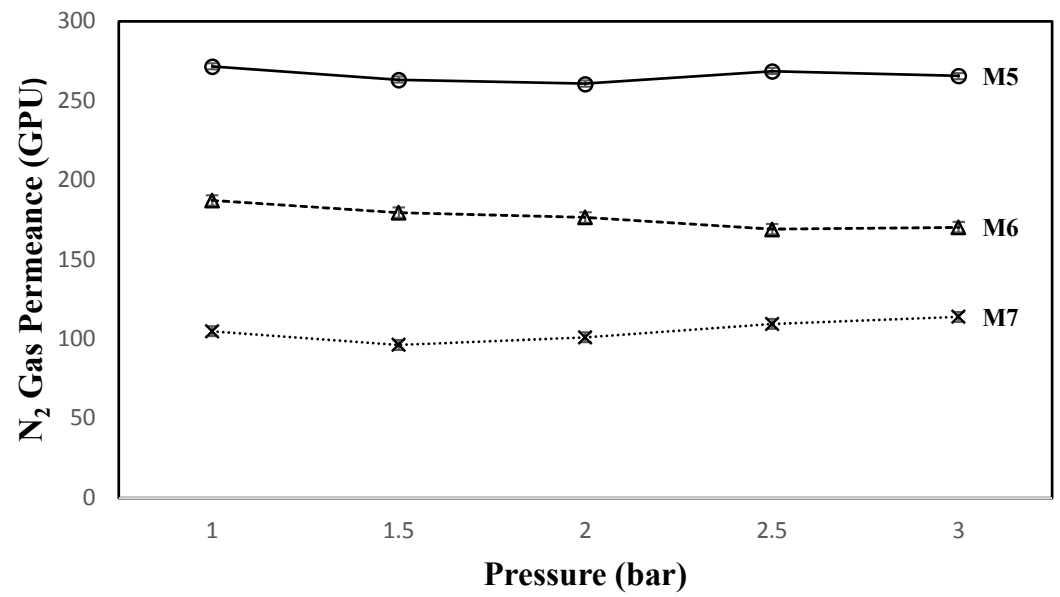

Figure $4 \mathrm{~N}_{2}$ Permeance for $\mathrm{CAB}$ membrane fabricated with different casting thickness of $150 \mu \mathrm{m}$ (M5), $250 \mu \mathrm{m}$ (M6), and $300 \mu \mathrm{m}$ (M7) with solvent evaporation time of $4.5 \mathrm{~min}$, polymer concentration of $4 \mathrm{wt} \%$ made up by blending three different molecular weights $(\mathrm{Mn})$ of 12,000, 30,000 and 70,000 at a ratio of 1:2:2, and solvent exchange drying time of 1 hour each for 2isopropyl alcohol and n-hexane, respectively

\subsubsection{Membrane Performance Test}

To test the membrane performance, the membranes (M5, M6, and M7) were assessed towards the permeance of $\mathrm{CO}_{2}$ and $\mathrm{N}_{2}$, respectively. The results of $\mathrm{CO}_{2}$ permeance obtained for M5 $(150 \mu \mathrm{m}), \mathrm{M} 6(250 \mu \mathrm{m})$ and M7 (300 $\mu \mathrm{m})$ at 1 bar to 3 bar were illustrated in
Figure 3. According to Figure 3, the decrease in membrane permeance performance can clearly be visible, where the $\mathrm{CO}_{2}$ permeance of M5 is the highest at $265.921 \pm 2.902 \mathrm{GPU}$ as compared to M6 (179.811 \pm 4.229 GPU) and M7 (165.628 \pm 3.399 GPU). From the results, it can be concluded 


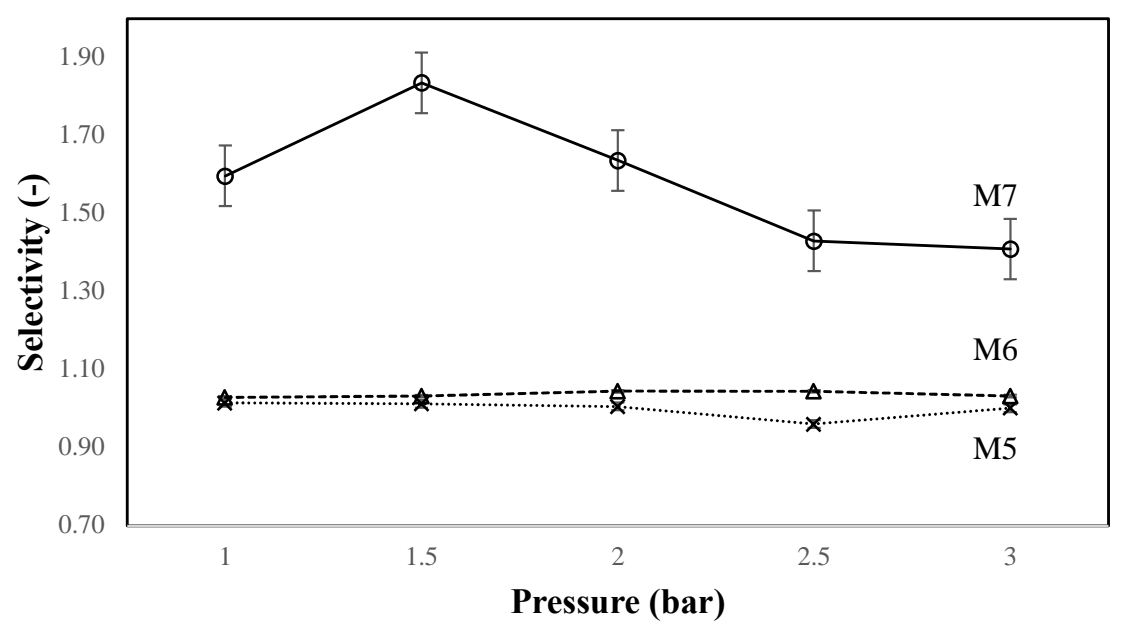

Figure $5 \mathrm{CO}_{2} / \mathrm{N}_{2}$ Selectivity for $\mathrm{CAB}$ membrane fabricated with different casting thickness of 150 $\mu \mathrm{m}$ (M5), $250 \mu \mathrm{m}$ (M6), and $300 \mu \mathrm{m}$ (M7) with solvent evaporation time of $4.5 \mathrm{~min}$, polymer concentration of $4 \mathrm{wt} \%$ made up by blending three different molecular weights $(\mathrm{Mn})$ of 12,000, 30,000 and 70,000 at a ratio of 1:2:2, and solvent exchange drying time of 1 hour each for 2isopropyl alcohol and n-hexane, respectively

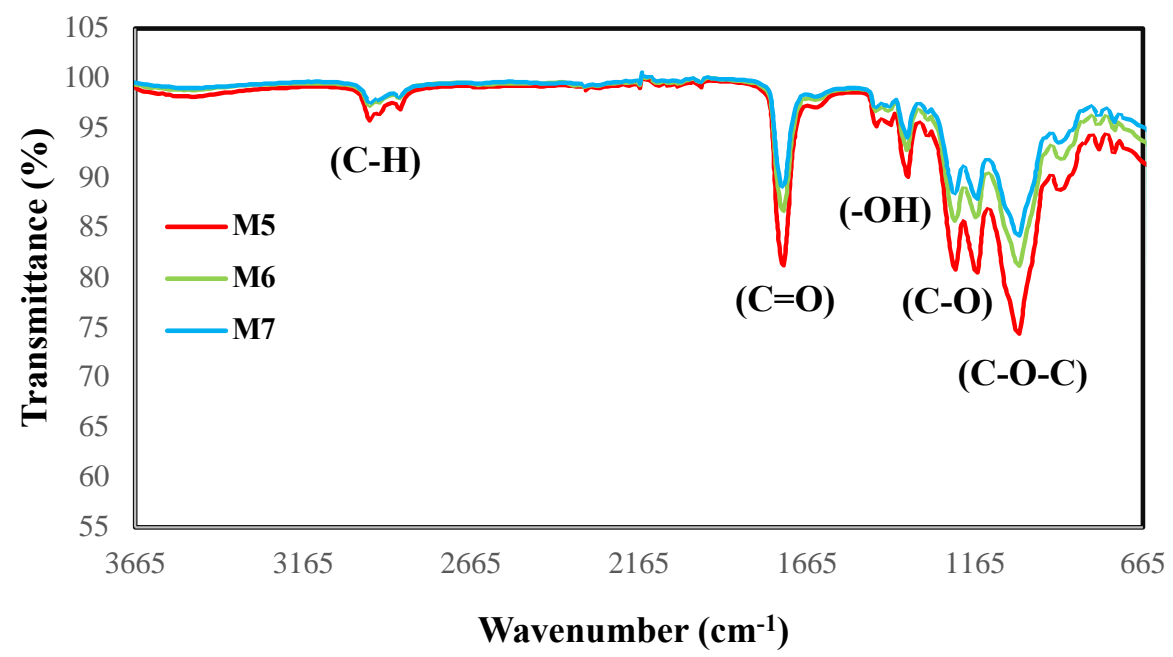

Figure 6 ATR-FTIR spectroscopy for CAB membrane fabricated with different casting thickness of $150 \mu \mathrm{m}$ (M5), $250 \mu \mathrm{m}$ (M6), and $300 \mu \mathrm{m}$ (M7) with solvent evaporation time of $4.5 \mathrm{~min}$, polymer concentration of $4 \mathrm{wt} \%$ made up by blending three different molecular weights $(\mathrm{Mn})$ of $12,000,30,000$ and 70,000 at a ratio of 1:2:2, and solvent exchange drying time of 1 hour each for 2 -isopropyl alcohol and $n$-hexane respectively

that the $\mathrm{CO}_{2}$ permeance increased with the reduction in the casting thickness of the CAB membrane. This is because the skin layer (selective layer) of the membrane decreases as the casting thickness decreases [5]. Hence, the permeance of the membrane increases with a thin membrane because the $\mathrm{CO}_{2}$ molecules are absorbed at a high level on the skin layer surface and then diffuse through the dense layer of the membrane [20]. Therefore, the best casting thickness was $150 \mu \mathrm{m}$ (M5) 


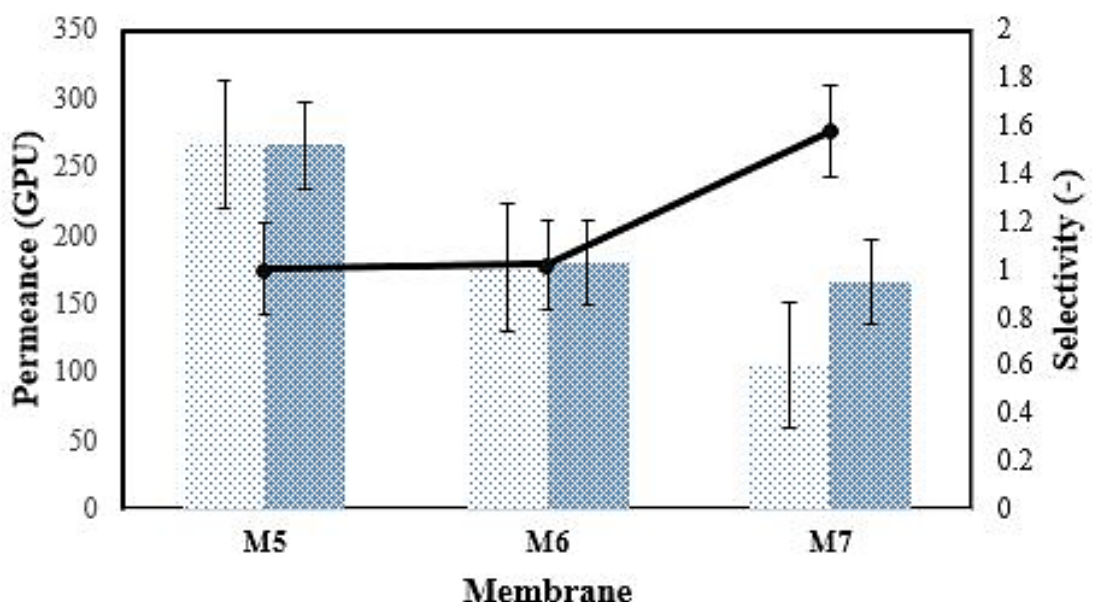

$\mathbf{N}_{2}$ Permeance $\mathrm{CO}_{2}$ Permeance $\longrightarrow \mathrm{CO}_{2} / \mathrm{N}_{2}$ Selectivity

Figure $7 \mathrm{CO}_{2}$ and $\mathrm{N}_{2}$ Permeance (Left) and Selectivity of $\mathrm{CO}_{2} / \mathrm{N}_{2}$ (right) for CAB membrane fabricated with fabricated with different casting thickness of $150 \mu \mathrm{m}$ (M5), $250 \mu \mathrm{m}$ (M6), and 300 $\mu \mathrm{m}$ (M7) with solvent evaporation time of $4.5 \mathrm{~min}$, polymer concentration of $4 \mathrm{wt} \%$ made up by blending three different molecular weights $(\mathrm{Mn})$ of 12,000, 30,000 and 70,000 at a ratio of 1:2:2, and solvent exchange drying time of 1 hour each for 2-isopropyl alcohol and n-hexane, respectively

with a $\mathrm{CO}_{2}$ permeance of $265.921 \pm$ 2.902 GPU.

Meanwhile, the results of $\mathrm{N}_{2}$ permeance obtained for M5 $(150 \mu \mathrm{m})$, M6 $(250 \mu \mathrm{m})$ and M7 $(300 \mu \mathrm{m})$ at 1 bar to 3 bar is shown in Figure 4. The results depicted in Figure 4 exhibits a similar trend to the results shown in Figure 3 where the increase in membrane permeance performance can clearly be visible as the casting thickness decreases. The membrane M5 $(150 \mu \mathrm{m})$ has the highest $\mathrm{N}_{2}$ permeance at $266.092 \pm 1.923 \mathrm{GPU}$ as compared to M6 $(250 \mu \mathrm{m})$ of 176.413 $\pm 3.067 \mathrm{GPU}$ and M7 $(300 \mu \mathrm{m})$ of $105.290 \pm 3.095$ GPU. The high $\mathrm{N}_{2}$ permeance of the M5 membrane was due to its thinner membrane thickness of $4.852 \pm 0.654 \mu \mathrm{m}$ as exhibited in Figure 2 (b). This is due to the improvement in the gas permeance of a membrane when the dense skin layer decreases [20]. This is further supported with studies carried out by Jawad et al. (2015) who concluded that a membrane with a thin layer accomplish a high efficiency [6]. In overall, the best casting thickness was $150 \mu \mathrm{m}$ (M5) with a $\mathrm{N}_{2}$ permeance of $266.092 \pm 1.923$ GPU.

Subsequently, the $\mathrm{CO}_{2} / \mathrm{N}_{2}$ selectivity of the $\mathrm{CAB}$ membrane fabricated at different casting thickness of M5 $(150 \mu \mathrm{m})$, M6 $(250 \mu \mathrm{m})$, and M7 $(300 \mu \mathrm{m})$ at 1 bar to 3 bar were studied. From Figure 5, it can be observed that the $\mathrm{CO}_{2} / \mathrm{N}_{2}$ selectivity increases from $0.9994 \pm 0.0099$ (M5) to $1.5819 \pm 0.0775(\mathrm{M} 7)$. This was due to the thickness of the selective layer of M7 which increased as the casting thickness increased, selectively allowing a specific measure of $\mathrm{CO}_{2}$ to diffuse through the thick membrane, assisted by the solution-diffusion mechanism [21]. Besides that, the higher selectivity of M7 was also the result of higher carbonyl $(\mathrm{C}=\mathrm{O})$ and hydroxyl $(\mathrm{O}-\mathrm{H})$ groups stretching vibrations, as shown in Figure 6 . According to Shan et al. [12], both 
$\mathrm{C}=\mathrm{O}$ and $\mathrm{O}-\mathrm{H}$ groups are the highly polar functional groups that can affect the gas separation performance. Hence, in this case, these increased polar functional groups $(\mathrm{C}=\mathrm{O}$ and $\mathrm{O}-\mathrm{H})$ interact with the non-polar $\mathrm{CO}_{2}$, improving the membranes (M3) $\mathrm{CO}_{2} / \mathrm{N}_{2}$ selectivity [22].

In summary, the overall separation performance of the $\mathrm{CAB}$ membrane based on the effect of casting thickness was shown in Figure 7. Based on Figure 7, membrane M6 $(250 \mu \mathrm{m})$ was preferable due to its better $\mathrm{CO}_{2}$ permeance of $179.811 \pm 4.229 \mathrm{GPU}$ and $\mathrm{CO}_{2} / \mathrm{N}_{2}$ selectivity of $1.0189 \pm$ 0.0074 . This results supports the findings of Firpo et al. [7] who concluded that that the permeance shows a strong decrease with increase in thickness but the selectivity does not change significantly in its value.

\subsection{Effect of Solvent Evaporation Time}

\subsubsection{Membrane Characterization}

SEM analysis had been carried out to study the membrane morphology and membrane thickness at different evaporation time. Figure 8 illustrates the surface morphology and crosssectional thickness for the cellulose acetate butyrate (CAB) membranes fabricated at different solvent evaporation time of $3.5 \mathrm{~min}(\mathrm{M} 1), 4$ $\min (\mathrm{M} 2), 4.5 \mathrm{~min}(\mathrm{M} 3)$ and $5 \mathrm{~min}$ (M4), respectively. According to Figure 8 (a, c, e and $\mathrm{g}$ ), the membrane surface remains rough across all solvent evaporation time. The rough surface was due to the hydrophobicity of the membrane surface which reduced the ability of hydrogen bonding formation with water that manipulated the surface morphology [23]. On the other hand, the solvent evaporation time affected the number of nodules on the membrane. With the increase in solvent evaporation time, the nodule distribution on the top surface also increases which is clearly visible from Figure 8 (a, c, e and g). When the membrane formation system loses the solvent environment, chain segments would lose mobility and cannot further adjust their configurations. The loss of solvent environment is too fast during the formation process of the M1 (3.5 min) membrane, and the nodule aggregation would stop at an intermediate stage. But for the formation process of the M4 (5 min) membrane, out-diffusion of solvent is slow enough. Therefore, due to the presence of the solvent atmosphere, the nodular structures can aggregate to form more structures [18].

Furthermore, based on Figure 8 (b, $\mathrm{d}$, f and $\mathrm{h}$ ), when the solvent evaporation time increased from 3.5 min (M1) to $5 \mathrm{~min}$ (M4), the membrane thickness increased from $7.168 \pm 1.083 \mu \mathrm{m}$ to $18.489 \pm 1.820$ $\mu \mathrm{m}$. This is because a longer evaporation time would form a less compact polymer region at the top of the casting membrane due to the evaporation of highly volatile solvent [24]. Hence, a longer evaporation time would consequently lead to the formation of an asymmetric membrane with a denser and thicker skin layer [25]. Additionally, the thickness of membrane M2 (4 min) also increased to $20.896 \pm 3.432 \mu \mathrm{m}$ which is similar to M4 $(18.489 \pm 1.820 \mu \mathrm{m})$. Meanwhile, the membrane fabricated at a solvent evaporation time of 4.5 min (M3) showed a thinner membrane of $8.995 \pm 1.083 \mu \mathrm{m}$ compared to $\mathrm{M} 2$ and M4. This phenomena can be explained by the compact characteristics of the $\mathrm{CAB}$ chains in the formation of the M3 membrane during the controlled solvent evaporation period ( $4.5 \mathrm{~min})$, forming a thin membrane [2]. 

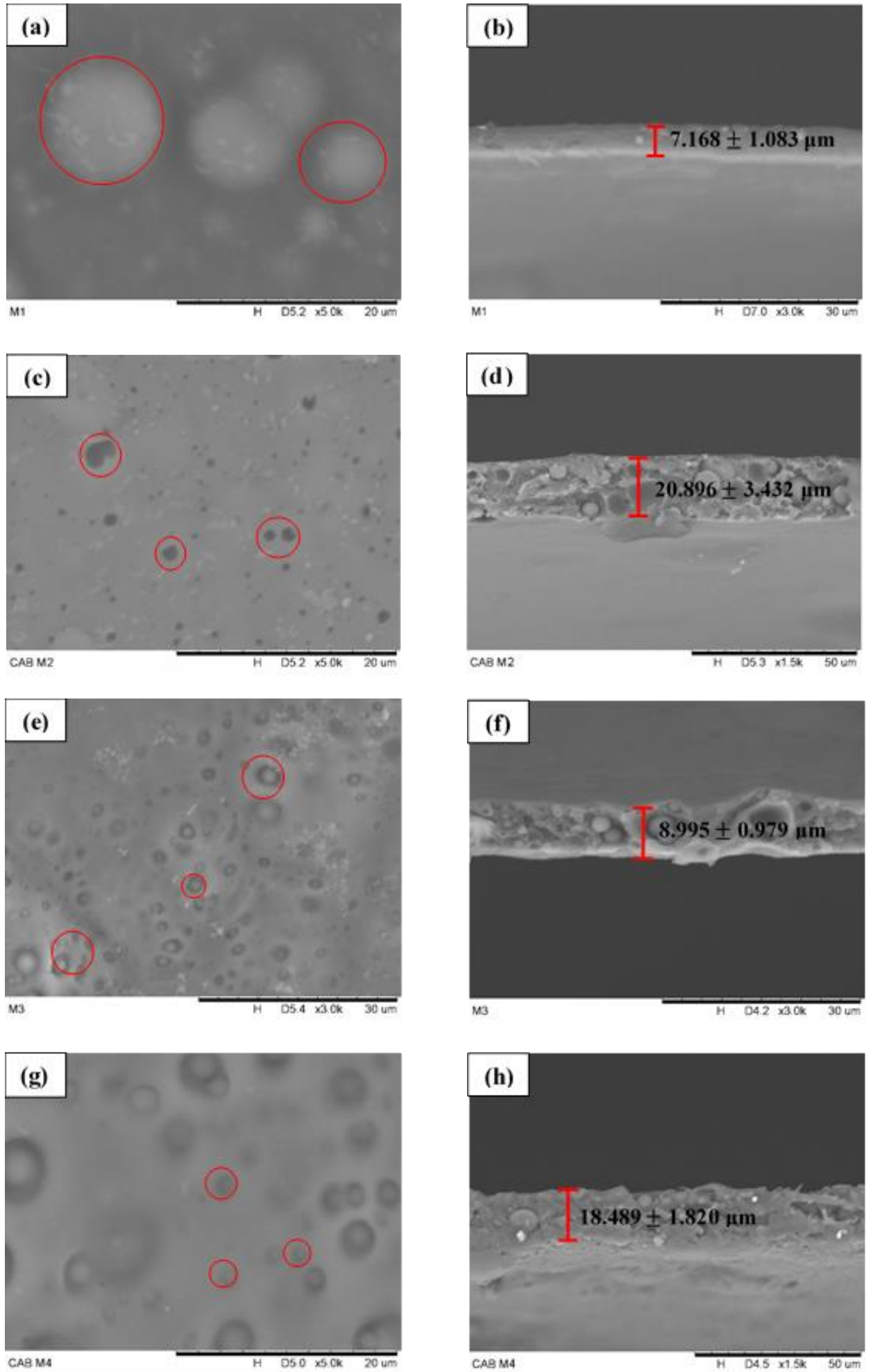

Figure 8 SEM micrographs of membrane surface (left) and cross-section (right) structure synthesized by using $4 \mathrm{wt} \%$ of $\mathrm{CAB}$ Polymer concentration made up by blending three different molecular weights $(\mathrm{Mn})$ of 12,000, 30,000 and 70,000 at a ratio of 1:2:2, casting thickness of $250 \mu \mathrm{m}$, and solvent exchange drying time of 1 hour for 2-isopropyl alcohol and n-hexane each, with different solvent evaporation time of (a-b) $3.5 \mathrm{~min}$ (M1), (c-d) 4 min (M2), (e-f) $4.5 \mathrm{~min}$ (M3) and (g-h) 5 min (M4)

Based on Figure 9, the membranes (M1, M2, M3 and M4) were tested by the ATR-FTIR spectroscopy to investigate the solvent evaporation 


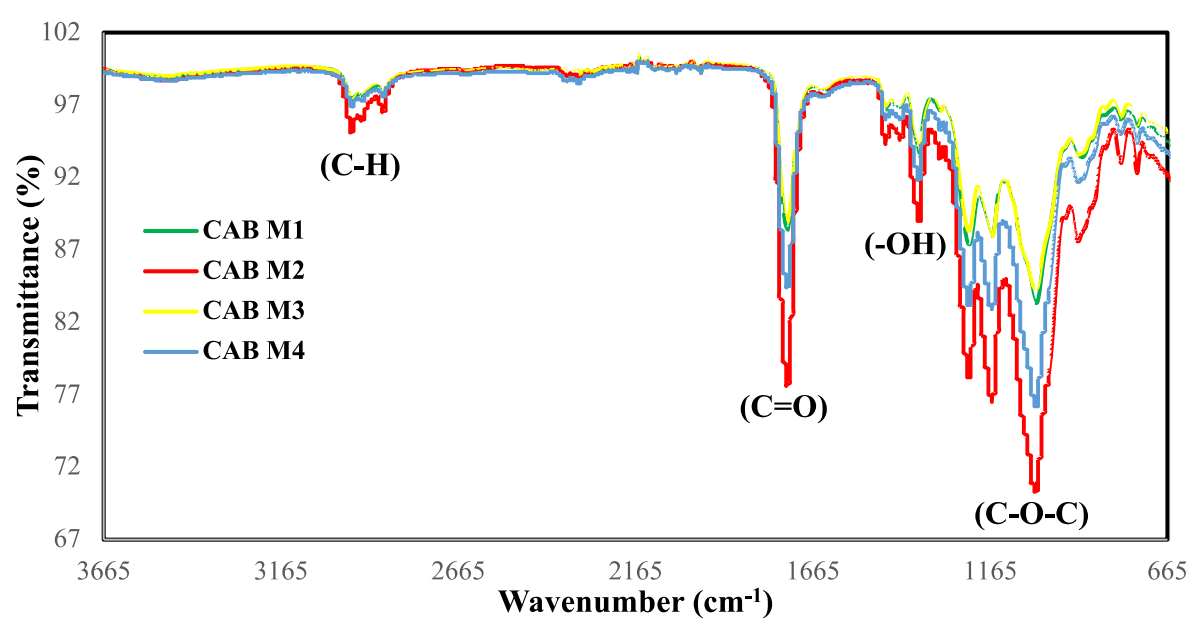

Figure 9 ATR-FTIR spectroscopy for $\mathrm{CAB}$ membrane fabricated with different solvent evaporation time of $3.5 \mathrm{~min}(\mathrm{M} 1), 4 \mathrm{~min}(\mathrm{M} 2), 4.5 \mathrm{~min}$ (M3) and $5 \mathrm{~min}$ (M4) with casting thickness of $250 \mu \mathrm{m}$, polymer concentration of $4 \mathrm{wt} \%$ made up by blending three different molecular weights $(\mathrm{Mn})$ of 12,000, 30,000 and 70,000 at a ratio of 1:2:2, and solvent exchange drying time of 1 hour each for 2-isopropyl alcohol and n-hexane, respectively

times on the functional groups of the CAB membrane. The transmittance peak at approximately $2965 \mathrm{~cm}^{-1}$ is attributed by $\mathrm{C}-\mathrm{H}$ stretching [26]. Meanwhile, the peak at around 1736 $\mathrm{cm}^{-1}$ is assigned to the carbonyl group vibration of carboxylic acid $(\mathrm{C}=\mathrm{O})$ groups, and the peak at $1159 \mathrm{~cm}^{-1}$ represents the stretching of acrylate groups (acrylic C-O bond) [27]. Further, the peak at $1038 \mathrm{~cm}^{-1}$ is referred to as the $\mathrm{C}-\mathrm{O}-\mathrm{C}$ stretching [28]. In addition, the peak at $1366 \mathrm{~cm}^{-1}$ is contributed by the $(-\mathrm{OH})$ group [22].

\subsubsection{Membrane Performance Test}

Membranes fabricated at a different solvent evaporation time of $3.5 \mathrm{~min}$ (M1), 4 min (M2), 4.5 min (M3), and 5 min (M4) were evaluated towards $\mathrm{CO}_{2}$ permeance by performing a single gas permeation test of $\mathrm{CO}_{2}$, as exhibited in Figure 10. Based on Figure 10, the $\mathrm{CO}_{2}$ permeance of M4 is the highest at $191.595 \pm 3.197$ GPU as compared to M3 (179.811 \pm 4.229 GPU), M2 $(80.973 \pm 3.198$ GPU) and M1 (59.698 \pm 2.204 GPU). This is due to the increase in solvent evaporation time during membrane fabrication which contributed to the increase of the $\mathrm{CO}_{2}$ permeance. With longer solvent evaporation duration, $\mathrm{CAB}$ polymer chains tend to rigidified with higher free volume and thus, improve the penetration of gasses through the resultant membrane [29]. However, the membrane M4 has a poor mechanical strength as the maximum withstanding pressure of M4 was only 2 bar. This could be due to the prolonged solventwater exchange which deformed the membrane structure, resulting in a reduced mechanical strength of the synthesized membrane [19]. Based on these results, the best solvent evaporation time was $4.5 \mathrm{~min}$ (M3) with a $\mathrm{CO}_{2}$ permeance of $179.811 \pm$ 4.229 GPU.

Next, the membranes fabricated at a different solvent evaporation time of $3.5 \mathrm{~min}$ (M1), $4 \mathrm{~min}$ (M2), $4.5 \mathrm{~min}$ (M3), and $5 \mathrm{~min}$ (M4) were tested towards $\mathrm{N}_{2}$ permeance by performing a single gas permeation test of $\mathrm{N}_{2}$ as 


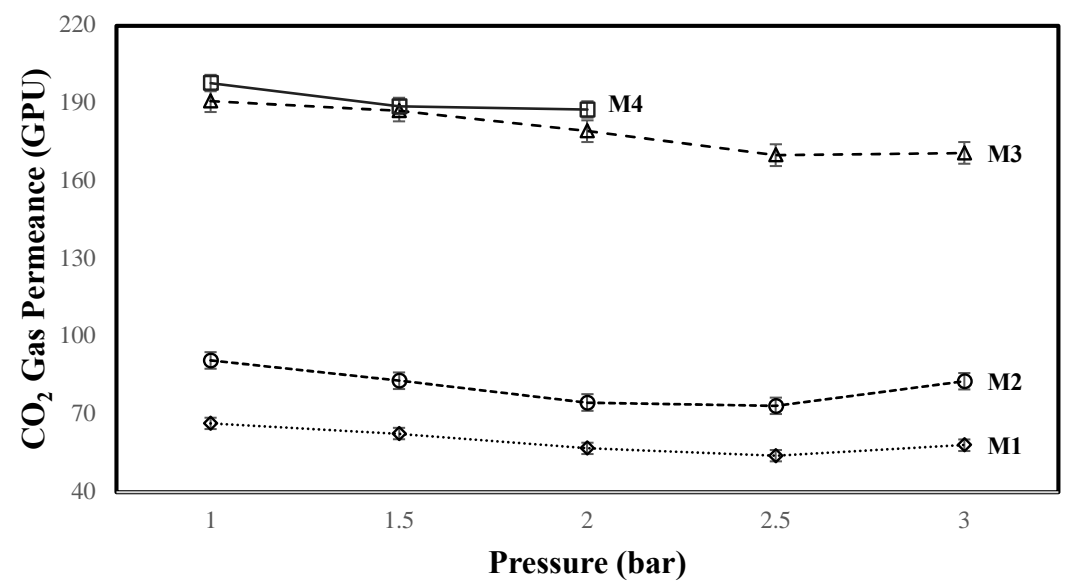

Figure $10 \mathrm{CO}_{2}$ Permeance for $\mathrm{CAB}$ membrane fabricated with different solvent evaporation time of $3.5 \mathrm{~min}$ (M1), $4 \mathrm{~min}$ (M2), $4.5 \mathrm{~min}$ (M3) and $5 \mathrm{~min}$ (M4) with casting thickness of $250 \mu \mathrm{m}$, polymer concentration of $4 \mathrm{wt} \%$ made up by blending three different molecular weights $(\mathrm{Mn})$ of $12,000,30,000$ and 70,000 at a ratio of 1:2:2, and solvent exchange drying time of 1 hour each for 2-isopropyl alcohol and n-hexane, respectively

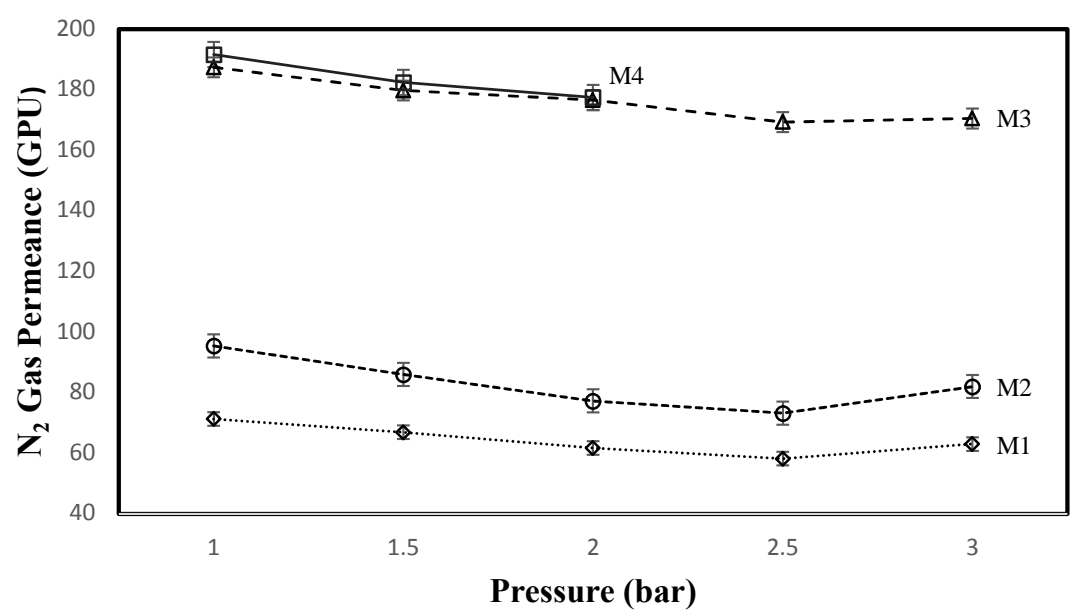

Figure $11 \mathrm{~N}_{2}$ Permeance for $\mathrm{CAB}$ membrane fabricated with different solvent evaporation time of $3.5 \mathrm{~min}$ (M1), $4 \mathrm{~min}(\mathrm{M} 2), 4.5 \mathrm{~min}$ (M3) and $5 \mathrm{~min}$ (M4) with casting thickness of $250 \mu \mathrm{m}$, polymer concentration of $4 \mathrm{wt} \%$ made up by blending three different molecular weights $(\mathrm{Mn})$ of $12,000,30,000$ and 70,000 at a ratio of 1:2:2, and solvent exchange drying time of 1 hour each for 2-isopropyl alcohol and n-hexane, respectively

demonstrated in Figure 11. From Figure 11, it can be seen that the M3 membrane has the highest $\mathrm{N}_{2}$ permeance of $176.413 \pm 3.067 \mathrm{GPU}$ compared to M2 of $82.840 \pm 3.817$ GPU and M1 of $64.290 \pm 2.249$ GPU at 1 to 3 bar. The high $\mathrm{N}_{2}$ permeance of the M3 membrane was due to its thinner membrane thickness of 8.995 $\pm 1.083 \mu \mathrm{m}$ as observed in Figure 8 (f) which is ideal for gas separation application as a thinner membrane enforces less flux resistance towards the membrane permeance, resulting in a higher permeance rate [22].

Meanwhile, the $\mathrm{CO}_{2} / \mathrm{N}_{2}$ selectivity of the $\mathrm{CAB}$ membrane fabricated at different solvent evaporation time of M1 (3.5 min), M2 (4 min), M3 (4.5 min) and M4 (5 min) at 1 bar to 3 bar were studied. From Figure 12, it can be observed that the $\mathrm{CO}_{2} / \mathrm{N}_{2}$ selectivity 


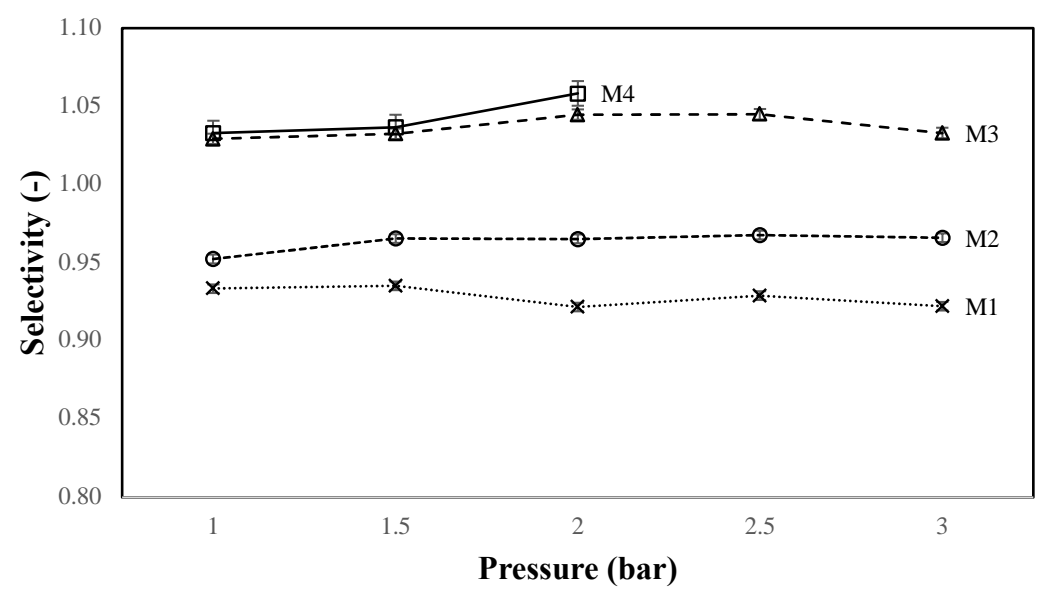

Figure $12 \mathrm{CO}_{2} / \mathrm{N}_{2}$ Selectivity of $\mathrm{CAB}$ membrane fabricated with different solvent evaporation time of $3.5 \mathrm{~min}$ (M1), $4 \mathrm{~min}$ (M2), $4.5 \mathrm{~min}$ (M3) and $5 \mathrm{~min}$ (M4) with casting thickness of 250 $\mu \mathrm{m}$, polymer concentration of $4 \mathrm{wt} \%$ made up by blending three different molecular weights $(\mathrm{Mn})$ of 12,000, 30,000 and 70,000 at a ratio of 1:2:2, and solvent exchange drying time of 1 hour each for 2-isopropyl alcohol and n-hexane, respectively

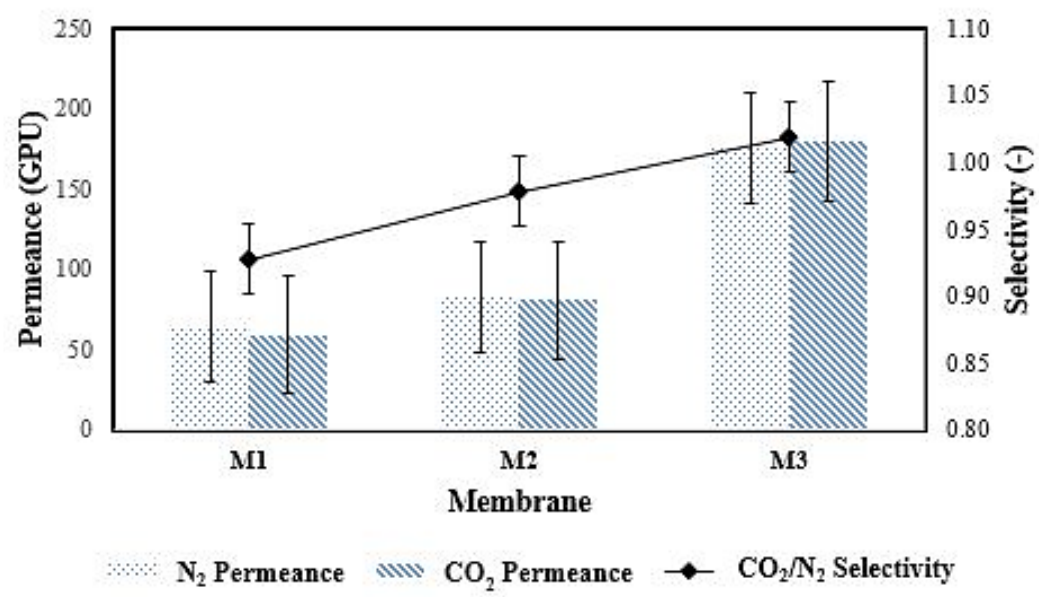

Figure $13 \mathrm{CO}_{2}$ and $\mathrm{N}_{2}$ Permeance (Left) and Selectivity of $\mathrm{CO}_{2} / \mathrm{N}_{2}$ (right) for $\mathrm{CAB}$ membrane fabricated with different solvent evaporation time of $3.5 \mathrm{~min}$ (M1), $4 \mathrm{~min}$ (M2), and $4.5 \mathrm{~min}$ (M3) with casting thickness of $250 \mu \mathrm{m}$, polymer concentration of $4 \mathrm{wt} \%$ made up by blending three different molecular weights (Mn) of 12,000, 30,000 and 70,000 at a ratio of 1:2:2, and solvent exchange drying time of 1 hour each for 2-isopropyl alcohol and n-hexane, respectively

increased from $0.9283 \pm 0.0028(\mathrm{M} 1)$ to $1.0189 \pm 0.0074(\mathrm{M} 3)$ as the solvent evaporation duration was increased from $3.5 \mathrm{~min}(\mathrm{M} 1)$ to $4.5 \mathrm{~min}(\mathrm{M} 3)$. This was as a result of higher $\mathrm{C}=\mathrm{O}$ and -OH group stretching vibrations exhibited by M3 when an ATR-FTIR spectroscopy test was carried out, as shown in Figure 9. According to Shan et al. (2012), both the carbonyl $(\mathrm{C}=\mathrm{O})$ and hydroxyl $(\mathrm{O}-\mathrm{H})$ groups are the highly polar functional groups that can affect the gas separation performance [12]. Hence, in this case, these increased polar functional groups $(\mathrm{C}=\mathrm{O}$ and $\mathrm{O}-\mathrm{H})$ interact with the nonpolar $\mathrm{CO}_{2}$, improving the membranes (M3) $\mathrm{CO}_{2} / \mathrm{N}_{2}$ selectivity [22]. 
In summary, the overall separation performance of the $\mathrm{CAB}$ membrane based on the effect of solvent evaporation time was shown in Figure 13. Based on Figure 13, membrane M3 (4.5 min) has the best $\mathrm{CO}_{2}$ permeance and $\mathrm{CO}_{2} / \mathrm{N}_{2}$ selectivity of $179.811 \pm$ 4.229 GPU and $1.0189 \pm 0.0074$, respectively. This results validates the findings of M. Mubashir et al. [29] which demonstrates that an increase in solvent evaporation time would cause the $\mathrm{CAB}$ polymer chains to rigidified, enhancing the penetration of gasses through the resultant membrane which would consequently improve the $\mathrm{CO}_{2}$ permeance of the membrane. In addition to that, an increase in both the $\mathrm{C}=\mathrm{O}$ and $-\mathrm{OH}$ groups stretching vibrations were exhibited by M3 in the ATR-FTIR spectroscopy test (Figure 9). This would improve the interaction between the highly polar functional groups $(\mathrm{C}=\mathrm{O}$ and $-\mathrm{OH})$ and the nonpolar $\mathrm{CO}_{2}$, improving the $\mathrm{CO}_{2} / \mathrm{N}_{2}$ selectivity of the membrane [22].

\subsection{CONCLUSION}

In conclusion, the Cellulose Acetate Butyrate (CAB) membranes with polymer blend of molecular weight $(\mathrm{Mn})$ of 12000,70000 and 3000 at a ratio of $1: 2: 2$, were successfully fabricated by optimizing the solvent evaporation time and casting thickness of the CAB membrane. The findings of this study validates that the solvent evaporation time influences the membrane morphology and membrane gas separation performance by a great deal. Based on the obtained results, the $\mathrm{CO}_{2} / \mathrm{N}_{2}$ selectivity was at $1.0189 \pm$ 0.0074 (M3) with a $\mathrm{CO}_{2}$ and $\mathrm{N}_{2}$ permeance of $179.811 \pm 4.229 \mathrm{GPU}$ and $176.413 \pm 3.067$ GPU, respectively, when the solvent evaporation time was at $4.5 \mathrm{~min}$. The increase in the duration of the solvent evaporation time caused an increase in the membranes performance due to the strengthened $\mathrm{CAB}$ polymer chains with higher free volume.

Moreover, the improvement of the $\mathrm{CAB}$ membranes performance was also due to the higher stretching vibration of the polar groups $(\mathrm{C}=\mathrm{O})$ and $(-\mathrm{OH})$ available in the membrane structure, which are highly attractive to the non-polar $\mathrm{CO}_{2}$. In addition to that, the membrane casting thickness is also an essential parameter for membrane fabrication as the properties of the membrane are dependent upon the membrane thickness. When the casting thickness was increased, the $\mathrm{CO}_{2}$ permeance of the membrane showed a decrease in performance from 265.921 \pm 2.902 GPU (M5) $(150 \mu \mathrm{m})$ to $165.628 \pm 3.399$ GPU (M7) $(300 \mu \mathrm{m})$ because of the selective layer of the membrane reduced as the casting thickness decreases. Thus, the permeance of the membrane increases with a thin membrane because the $\mathrm{CO}_{2}$ molecules are absorbed at a high level on the skin layer surface and then diffuse through the dense layer of the membrane. Hence, the preferable casting thickness was at $250 \mu \mathrm{m}$ (M6) due to its better $\mathrm{CO}_{2}$ permeance of $179.811 \pm 4.229$ GPU and $\mathrm{CO}_{2} / \mathrm{N}_{2}$ selectivity of $1.0189 \pm 0.0074$.

\section{ACKNOWLEDGEMENTS}

The authors would like to offer their appreciation to the Ministry of Higher Education Malaysia (MOHE) for approving Fundamental Research Grant Scheme (FRGS) (MOHE Ref No:FRGS/1/2015/TK02/CURTIN/03/0 1) and Cost Centre: 001048. We would also like to thank LRGS USM (No: 304/PJKIMIA/6050296/U124) and Curtin Cost Centre: 001047. 


\section{REFERENCES}

[1] Sreedhar, I., Vaidhiswaran, R., Kamani, B. M., Venugopal, A. 2017. Process and Engineering Trends in Membrane based Carbon Capture. J. Renew. Sustain Ener. 68: 659-684.

[2] Lee, R. J., Jawad, Z. A., Ahmad, A. L., Ngo, J. Q., Chua, H. B. 2017. Improvement of $\mathrm{CO}_{2} / \mathrm{N}_{2}$ Separation Performance by Polymer Matrix Cellulose Acetate Butyrate. IOP Conference Series: J. Mat. Sci. Eng. 206: 012072.

[3] IEAGHG. 2014 Assessment of Emerging CO2 Capture Technologies and Their Potential to Reduce Costs.

[4] Zhang, Y., Sunarso, J., Liu, S., Wang, R. 2013. Current Status and Development of Membranes for $\mathrm{CO}_{2} / \mathrm{CH}_{4}$ Separation: A Review. Int. J. GHG Control. 12: 84-107.

[5] Ahmad, Olatunji S. Y., Jawad, Z. A. 2017. Thickness Effect on the Morphology and Permeability of $\mathrm{CO}_{2} / \mathrm{N}_{2}$ Gases in Asymmetric Polyetherimide Membrane. $J$. Phys. Sci. 28: 201-213.

[6] Jawad, Z., A. L. Ahmad, S. C. Low, Zein, S. 2015. Incorporation of Inorganic Carbon Nanotubes Fillers into the $\mathrm{Ca}$ Polymeric Matrix for Improvement in $\mathrm{Co}_{2} / \mathrm{N}_{2}$ Separation. J. Nanos. 11: 69-79.

[7] Firpo, G., Angeli, E., Repetto, L., Valbusa, U. 2015. Permeability thickness Dependence of Polydimethylsiloxane (PDMS) Membranes. J. Membr Sci. 481: 1-8.

[8] Iqbal, M., Man, Z., Mukhtar, H., Dutta, B. K. 2008. Solvent Effect on Morphology and $\mathrm{CO}_{2} / \mathrm{CH}_{4}$ Separation Performance of
Asymmetric Polycarbonate Membranes. J. Membr Sci. 318: 167-175.

[9] Hołda, A. K., Aernouts, B., Saeys, W., Vankelecom, I. F. J. 2013. Study of Polymer Concentration and Evaporation Time as Phase Inversion Parameters for Polysulfonebased SRNF Membranes. $J$. Membr Sci. 442: 196-205.

[10] Haponska, M., Trojanowska, A., Nogalska, A., Jastrzab, R., Gumi, T., Tylkowski, B. 2017. PVDF Membrane MorphologyInfluence of Polymer Molecular Weight and Preparation Temperature. J. Polym. 9: 718.

[11] Ahmad, A. L., Jawad, Z. A., Low, S. C., Sharif Zein, S. H. 2013. The Functionalization of Beta-cyclodextrins on Multi Walled Carbon Nanotubes: Effects of the Dispersant and Non Aqueous Media. Current Nanoscience. 9: 93-102.

[12] Shan, M., Xue, Q., Jing, N., Ling, C., Zhang, T., Yan, Z., Zheng, J. 2012. Influence of Chemical Functionalization on the CO2/N2 Separation Performance of porous Graphene Membranes. J. Nanoscale. 4: 5477-5482.

[13] Lee, R. J., Jawad, Z. A., Ahmad, A. L., Chua, H. B. 2018. Incorporation of Functionalized Multi-walled Carbon Nanotubes (MWCNTs) into Cellulose Acetate Butyrate (CAB) Polymeric Matrix to Improve the CO2/N2 Separation. Process Safety and Environmental Protection. 117: 159-167.

[14] Lalia, B. S., Kochkodan, V., Hashaikeh, R., Hilal, N. 2013. A Review on Membrane Fabrication: Structure, Properties and Performance Relationship. $J$. Desal. 326: 77-95. 
[15] Ye, F., J. M. Zhang, and J. Zhang. 2015. Gas Separation Properties of Cellulose Acetate Butyrate/Mwcnts Mixed Matrix Membranes. Acta Polymerica Sinica. 12: 1396-1401.

[16] Khursheed, A. 2007. Scanning Electron Microscope.

[17] Georg Ramer, Lendl., B., 2013. Attenuated Total Reflection Fourier Transform Infrared Spectroscopy. Encyclopedia of Analytical Chemistry,

[18] Yiming Zeng, Zhigang Wang, Lijun Wan, Yanqiao Shi, Guanwen Chen, Bai., C. 2003. Surface Morphology and Nodule Formation Mechanism of Cellulose Acetate Membranes by Atomic Force Microscopy. Institute of Chemistry, Chinese Academy of Sciences, Beijing 100080, People's Republic of China.

[19] Jawad, Z., A. L. Ahmad, S. C. Low, Zein, S. 2015. Influence of Solvent Exchange Time on Mixed Matrix Membrane Separation Performance for $\mathrm{CO} 2 / \mathrm{N} 2$ and a Kinetic Sorption Study. J. Membr Sci. 476: 590601.

[20] Pakizeh, M., Mansoori, S. A. A., Pourafshari Chenar, M., NamvarMahboub, M. 2013. Modification of PSf Membrane Nanostructure using Different Fabrication Parameters and Investigation of the $\mathrm{CO} 2$ Separation Properties of PDMSCoated PSf Composite Membranes. Brazilian J. Chem Eng. 30: 345-354.

[21] Xing, D. Y., Peng, N., Chung, T.-S. 2010. Formation of Cellulose Acetate Membranes via Phase Inversion Using Ionic Liquid, [BMIM]SCN, As the Solvent. J. Ind. Eng Chem Res. 49: 8761-8769.
[22] Lee, R. J., Jawad, Z. A., Ahmad, A. L., Chua, H. B. 2018. Incorporation of Functionalized Multi-walled Carbon Nanotubes (MWCNTs) into Cellulose Acetate Butyrate (CAB) Polymeric Matrix to Improve the CO2/N2 Separation. J. Process Saf. Environ. 117: 159-167.

[23] Du, J. R., Peldszus, S., Huck, P. M., Feng, X. 2009. Modification of Poly(vinylidene fluoride) Ultrafiltration Membranes with Poly(vinyl alcohol) for Fouling Control in Drinking Water Treatment. J. Water Res. 43: 4559-4568.

[24] Jami'an, H. Hasbullah, F. Mohamed, N. Yusof, N. Ibrahim, Ali, R. R. 2017. Effect of Evaporation Time on Cellulose Acetate Membrane for Gas Separation. IOP Conference Series: J. Ear. Env. Sci. 36.

[25] Altun, V., Remigy, J.-C., Vankelecom, I. F. J. 2017. UVcured Polysulfone-based Membranes: Effect of Co-solvent Addition and Evaporation Process on Membrane Morphology and SRNF Performance. J. Membr Sci. 524: 729-737.

[26] Lavorgna, M., Romeo, V., Martone, A., Zarrelli, M., Giordano, M., Buonocore, G. G., Qu, M. Z., Fei, G. X., Xia, H. S. 2013. Silanization and Silica Enrichment of Multiwalled Carbon Nanotubes: Synergistic Effects on The Thermalmechanical Properties of Epoxy Nanocomposites. European Poly J. 49: 428-438.

[27] Suttiwijitpukdee, N., Sato, H., Zhang, J., Hashimoto, T., Ozaki, Y. 2011. Intermolecular Interactions and Crystallization Behaviors of Biodegradable Polymer Blends between Poly 
(3-hydroxybutyrate) and Cellulose Acetate Butyrate Studied by DSC, FT-IR, and WAXD. J. Polym. 52: 461-471.

[28] Lou, Y., Liu, G., Liu, S., Shen, J., Jin, W. 2014. A Facile Way to Prepare Ceramic-supported Graphene Oxide Composite Membrane via Silane-graft
Modification. J. Appl. Surf. Sci. 307: 631-637.

[29] M. Mubashir, Y. Y. Fong, C. T. Leng, Keong, L. K. 2018. Enhanced Gases Separation of Cellulose Acetate Membrane Using N-Methyl-1-2 Pyrrolidone as Fabrication Solvent. Intl. J. A. Mech. Eng. 15: 4978-4986. 